This item was submitted to Loughborough's Research Repository by the author.

Items in Figshare are protected by copyright, with all rights reserved, unless otherwise indicated.

\title{
Vented confined explosions involving methane/hydrogen mixtures
}

PLEASE CITE THE PUBLISHED VERSION

http://dx.doi.org/10.1016/j.ijhydene.2010.02.084

\section{PUBLISHER}

(c) International Association for Hydrogen Energy. Published by Elsevier Ltd.

\section{VERSION}

AM (Accepted Manuscript)

\section{LICENCE}

CC BY-NC-ND 4.0

\section{REPOSITORY RECORD}

Lowesmith, Barbara J., Christopher Mumby, Geoffrey Hankinson, and J.S. Puttock. 2014. "Vented Confined Explosions Involving Methane/hydrogen Mixtures". figshare. https://hdl.handle.net/2134/15089. 
This item was submitted to Loughborough's Institutional Repository (https://dspace.lboro.ac.uk/) by the author and is made available under the following Creative Commons Licence conditions.

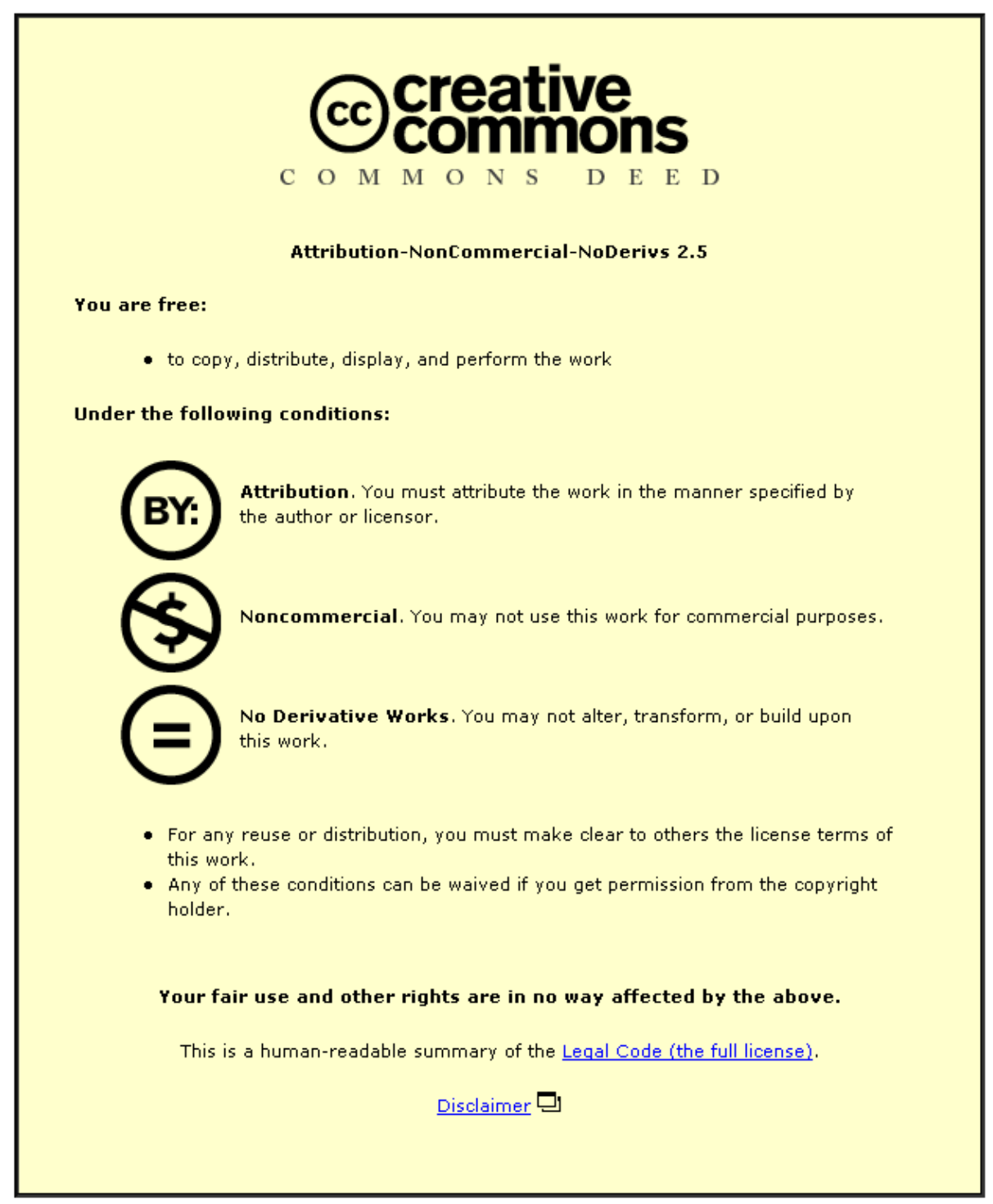

For the full text of this licence, please go to: http://creativecommons.org/licenses/by-nc-nd/2.5/ 


\title{
Vented Confined Explosions Involving Methane/Hydrogen
}

\section{Mixtures}

\author{
Lowesmith, B.J. ${ }^{\text {a } *}$, Mumby, C. ${ }^{\text {, }}$ Hankinson, G. ${ }^{\text {a }}$ and Puttock, J.S. ${ }^{\text {c }}$ \\ a Chemical Engineering Department, Loughborough University, UK \\ b GL Noble Denton, Loughborough, UK \\ c Shell Global Solutions (UK), Chester, UK
}

Received

\begin{abstract}
The EC funded Naturalhy project is assessing the potential for using the existing gas infrastructure for conveying hydrogen as a mixture with natural gas (methane). The hydrogen could then be removed at a point of use or the natural gas/hydrogen mixture could be burned in gas fired appliances thereby providing reduced carbon emissions compared to natural gas. As part of the project, the impact on the safety of the gas system resulting from the addition of hydrogen is being assessed. A release of a natural gas/hydrogen mixture within a vented enclosure (such as an industrial housing of plant and equipment) could result in a flammable mixture being formed and ignited. Due to the different properties of hydrogen, the resulting explosion may be more severe for natural gas/hydrogen mixtures compared to natural gas. Therefore, a series of large scale explosion experiments involving methane/hydrogen mixtures has been conducted in a 69.3

\footnotetext{
* Corresponding author, Fax +44 1509 223923, email address: b.j.lowesmith@lboro.ac.uk
} 
$\mathrm{m}^{3}$ enclosure in order to assess the effect of different hydrogen concentrations on the resulting explosion overpressures. The results showed that adding up to $20 \%$ by volume of hydrogen to the methane resulted in a small increase in explosion flame speeds and overpressures. However, a significant increase was observed when 50\% hydrogen was added. For the vented confined explosions studied, it was also observed that the addition of obstacles within the enclosure, representing congestion caused by equipment and pipework, etc, increased flame speeds and overpressures above the levels measured in an empty enclosure. Predictions of the explosion overpressure and flame speed were also made using a modified version of the Shell Global Solutions model, SCOPE. The modifications included changes to the burning velocity and other physical properties of methane/hydrogen mixtures. Comparisons with the experimental data showed generally good agreement.

Keywords: Methane and hydrogen explosions, confined vented explosions, explosion modelling

\section{Background}

Hydrogen is seen as an important energy carrier for the future which offers carbon free emissions at the point of use. However, transition to the hydrogen economy is likely to be lengthy and will take considerable investment with major changes to the technologies required for the manufacture, transport and use of hydrogen. In order to facilitate the transition to the hydrogen economy, the EC funded project Naturalhy is studying the potential for the existing natural gas pipeline networks to transport hydrogen from manufacturing sites to hydrogen users. The hydrogen, introduced into the pipeline network, would mix with the natural gas. The end-user may then extract the hydrogen for use in fuel cell applications or burn the gas mixture directly within existing gas-fired 
appliances, thereby reducing carbon emissions compared to natural gas. Using the existing pipeline network to convey hydrogen in this way would enable hydrogen production and hydrogen fuelled applications to become established prior to the development of a dedicated hydrogen transportation system, which would require considerable capital investment and time for construction.

However, the existing gas pipeline networks are designed, constructed and operated based on the premise that natural gas is the material to be conveyed. Hydrogen has different chemical and physical properties which may adversely affect the integrity or durability of the pipeline network, or which may increase the risk presented to the public. For these reasons, the Naturalhy project (www.naturalhy.net) has been initiated to assess the feasibility and impact of introducing hydrogen into a natural gas pipeline system. Determining any change in risk to the public is a major part of this project. As part of this work, the consequences of explosions following a release of methane/hydrogen within an enclosure (typical of that found in an industrial or commercial environment) have been assessed by conducting large scale experiments and undertaking complementary modelling studies.

\section{Introduction}

Hydrogen is a more reactive gas than methane (the main constituent of natural gas) and has a considerably higher laminar burning velocity than methane (approximately $2.6 \mathrm{~m} \mathrm{~s}^{-1}$ compared to $0.35 \mathrm{~m} \mathrm{~s}^{-1}$ for methane [1]. The speed at which the combustion reaction takes place within a gas/air mixture directly affects the resulting pressure generation as a pressure wave develops in front of the flame, particularly in unconfined or partially confined situations where the flame is able to accelerate. Consequently, a series of large scale experiments were undertaken within an enclosure representing an industrial housing 
or a room in a commercial premises. The enclosure had one open end wall representing a vent with a low failure pressure (such as a window or large doorway). The explosions studied involved methane and methane/hydrogen mixtures containing up to $50 \%$ by volume hydrogen. Explosion severity can be further increased if obstacles are present within the gas cloud giving rise to turbulence which further enhances the flame speeds and hence pressure generation. Therefore, some experiments involved the use of pipework obstacles (called congestion).

During the Naturalhy project, fundamental data has been obtained on laminar and turbulent burning velocities of methane/hydrogen mixtures [2,3]. This data has been used to modify an existing mathematical model, SCOPE, which was originally developed to predict the flame speed and overpressure developed by vented confined explosions involving hydrocarbon/air mixtures [4]. The modified model predictions have then been compared with the experimental results.

\section{Experimental details}

\subsection{Experimental Arrangement}

The test rig enclosure was constructed from steel and measured $8.25 \mathrm{~m}$ by $3 \mathrm{~m}$ by $2.8 \mathrm{~m}$ high. One side (3 m by $2.8 \mathrm{~m}$ high) was completely open. This side was covered by polythene sheet to allow a gas-air mixture to be held within the enclosure prior to ignition, whilst forming a low pressure vent following ignition. The enclosure could also accommodate pipework obstacles to form congestion. The introduction of congestion in the form of pipework would be expected to increase explosion overpressures due to the increased turbulence leading to increased flame speeds. During the test programme, tests were conducted with and without 17 pipework obstacles in order to study this effect. The 
pipes were $3 \mathrm{~m}$ long, $0.18 \mathrm{~m}$ in diameter and made from polyethylene. They were supported horizontally across the enclosure as shown in Figure 1.

Methane and hydrogen were introduced into the enclosure from separate gas supplies and then the mixture recirculated using an external recirculation system containing a fan, as shown on Figure 1. Oxygen cells were used to measure oxygen depletion (and hence total gas concentration) during the test rig filling process and provided instantaneous readings on the SCADA based logging system in the remotely located control room. This system also controlled the gas filling process. Gas samples were also drawn from the enclosure through $6.25 \mathrm{~mm}$ diameter tubing to on-line analysers which enabled the hydrogen and methane concentrations to be measured individually. Gas filling continued until the correct methane/hydrogen-in-air mixture had been achieved and recirculation continued until the mixture was uniform throughout the enclosure. As explosion overpressure is related to the composition of a gas-air mixture, the composition was chosen such that the maximum overpressures would be expected, that is, with an Equivalence Ratio of about 1.1, slightly rich of stoichiometric.

Once the correct mixture was formed, the recirculation system was isolated from the test rig and the mixture was ignited by a single electrical spark activated at a known time by a computer controlled system which also activated the data logging devices. The spark ignitor was located either at the centre of the enclosure, or close to the centre of the rear wall as shown on Figure 1. The flame then developed through the enclosure, causing the polythene to fail and allowing the flame to vent outside the enclosure.

\subsection{Scientific Measurements}


The progression of the flame throughout the explosion chamber was determined by 20 flame ionisation probes (IPs). Each probe consisted of two electrodes separated by a small gap (typically $10 \mathrm{~mm}$ ) that provides a high electrical resistance. As the flame passes between the two electrodes, the presence of the ions lowers the resistance across the gap and triggers a TTL (Transistor-Transistor Logic) voltage step output from a purpose-built electronic circuit. This voltage acts to terminate a computer based counting register on a counter board. Counting in the registers was initiated at the time of ignition at a known count frequency and hence an accurate time of arrival of the flame at the IP is obtained. Data from successive probes enables flame speeds to be calculated. The accuracy of the system has been checked previously by comparing it with cine records and other flame detection systems less suitable for large scale explosion experiments and has been shown to have an accuracy of better than a millisecond for natural gas explosions. The signals from the IPs were recorded on a PC based logging system at a rate of $100 \mathrm{kHz}$.

The explosion overpressures were measured using 10 pressure transducers. Six were located inside the enclosure and fixed to the floor within boxes. Four were installed within aerodynamic housings such that they measured the free field overpressure and located outside the vent (see Figure 2). A transient recorder was used to record the overpressure developed inside and outside the enclosure during the tests that were ignited. This logger recorded at a rate of $50 \mathrm{kHz}$. The pressure traces recorded were post-processed and a 1.5 ms rolling average applied to remove short duration spikes and noise. The maximum overpressure and time of occurrence were then identified.

The flame speed emerging from the vent was also determined from successive frames of high speed video footage. 


\section{Experimental Test programme and Results}

Table 1 summarises the test conditions of 10 tests which studied methane, 80:20 methane:hydrogen and 50:50 methane:hydrogen mixtures (by volume). The tests were ignited centrally and at the rear, with and without pipework congestion. The Table also summarises the average peak pressure and the maximum overpressure measured at any location within the enclosure. Generally, the maximum overpressure occurred at the rear of the test rig furthest from the vent. However, for tests ignited at the rear and involving a 50:50 methane:hydrogen mixture, where a high speed flame was produced, the highest overpressure occurred near the vent.

The flame speed at the vent was determined over the first $1 \mathrm{~m}$ from the vent using footage from a high speed video viewing the vent at 90 degrees (except in the case of Tests 5 and 9, where the flame speed was estimated from a camera viewing the vent at 45 degrees over a distance of $2 \mathrm{~m}$ ). These flame speeds are summarized on Table 1.

Figures 3 and 4 show typical overpressure profiles captured from the transducers located within the enclosure during tests involving a relatively low speed and high speed flame respectively.

Using the data from the IPs, Figure 5 shows the time of flame arrival within the enclosure for the tests ignited at the rear of the enclosure (6 to 10) without and with the pipework congestion. As can be seen, the addition of hydrogen to the fuel resulted in significantly earlier times of flame arrival at the vent, indicating higher flame speeds. This result can be explained by the higher burning velocity of hydrogen compared to methane, which increases the burning velocity of the methane/hydrogen mixtures. The addition of 
pipework congestion further reduced the time of arrival at the vent, that is, a higher flame speed was generated.

A close relationship between the maximum overpressure and the flame speed at the vent was observed, as can be seen on Figure 6. Figure 7 summarises the results of all tests in terms of the maximum overpressure measured within the enclosure. As can be seen, increasing the concentration of hydrogen, resulted in increased overpressures. However, the addition of $20 \%$ hydrogen to methane resulted in a modest increase in overpressure but the addition of $50 \%$ hydrogen to methane resulted in significantly higher overpressures. Considering the overpressures measured at all locations during the tests with an empty enclosure, the overpressures measured during tests with an 80:20 methane:hydrogen mixture were a factor of about 1.2 greater than those measured during the corresponding methane test. However, for the 50:50 mixture, the factor was about 3 to 4 . Figure 7 also shows that higher overpressures resulted when the ignition position was at the rear of the chamber compared to the centre and when pipework obstacles were added. The addition of pipework obstacles increased turbulence and hence increased the flame speed and the resulting overpressure.

For the rear ignition cases, the addition of pipework congestion resulted in overpressures for the 80:20 and 50:50 methane:hydrogen mixtures exceeding 1 bar with vent flame speeds over $250 \mathrm{~m} \mathrm{~s}^{-1}$, a level which would be expected to cause major collapse of most industrial structures and process plant. 


\section{Mathematical Modelling}

Shell Global Solutions have developed a model called SCOPE (Shell Code for Overpressure Predictions in gas Explosions) to predict the flame speed and overpressure generated in a vented confined explosion [4]. The model is phenomenologically based, comprising various sub models for physical processes such as 'grid' turbulence generation, burning velocity and flow from the vent. It is ideally suited to model confined vented explosions in the kind geometry of the test rig described in this paper.

Ignition is assumed to take place at the back wall (opposite the vent) and the flame front is modelled as being initially hemispherical in shape and expanding until the edge of the flame front reaches the walls of the enclosure. The unburnt mass is monitored using expressions for the rate of consumption by the flame and the mass flow through the vent. Self-acceleration of the flame is taken into account, whereby the expanding laminar flame develops wrinkles in the flame front that increase the flame area and the rate of fuel consumption.

Turbulence can be generated by obstacles or congestion, that is, solid bodies in the path of the flow of gas/air mixture ahead of the flame front, which act to increase the turbulent burning velocity and thus the flame speed. In order to be able to represent real pipework and vessels on a process site which form the 'congestion', the model requires an idealised representation of the congestion to be input. This representation takes the form of a series of 'grids' perpendicular to the flow field, where, within each grid, the user can specify several cylindrical or rectangular profile obstacles. Each grid has an area blockage and a representative size of the obstacles which both affect the generation of turbulence. The turbulence model is semi-empirical and is calculated using an expression which is a function of the drag that a grid of obstacles exerts on the flow. 
Overpressure generation is a function of various parameters, but essentially the flame speed is the dominant factor. The flame speed depends on the burning velocity of the fuel gas which can vary greatly if turbulence is present. The turbulent burning velocity is calculated using expressions which require the laminar burning velocity and the Markstein number for the fuel/air mixture concerned.

\subsection{Modifications to the Model}

SCOPE has been validated against various hydrocarbon experiments and has the ability to predict pure hydrogen gas explosions but not mixtures of these gases. To use the model for the Naturalhy project, it was necessary to modify the model.

In particular, the burning velocity of the natural gas/hydrogen mixtures needed to be characterised. This was achieved using data generated from experiments performed within the Naturalhy project on laminar and turbulent burning velocities of natural gas/hydrogen mixtures $[2,3]$. This data showed that the laminar and turbulent burning velocity increased with the amount of hydrogen added to methane. Furthermore, a 50:50 methane:hydrogen mixture exhibited a different response to turbulence than pure methane or an 80:20 mixture. The laminar burning velocity data was obtained at an elevated temperature (360K) for practical reasons, so it was necessary to temperature correct this data. This was achieved by fitting a power law [5] through results from kinetic modelling performed at 250, 300, 330 and $360 \mathrm{~K}$ for a range of fuels and equivalence ratios, assuming a relationship describing the variation of laminar burning velocity with the initial temperature of the fuel/air mixture of the form:

$$
\frac{u_{1}}{u_{0}}=\left(\frac{T_{1}}{T_{0}}\right)^{m}
$$


where $u_{0}, u_{1}$ are the laminar burning velocities for a gas/air mixture at an initial temperature of $T_{0}, T_{1}$ respectively. Polynomial functions were then fitted to the derived values of the exponent $m$ as a function of equivalence ratio. The resulting relationships were then applied to the experimental values obtained at $360 \mathrm{~K}$, setting the initial temperature at $298 \mathrm{~K}[6]$.

The stretch Markstein numbers (Ma) were also derived during the experiments for each fuel composition, this parameter affects the turbulent burning velocity calculation in the SCOPE sub model [7]. For stoichiometric methane/air mixtures, the Markstein number used by SCOPE is 3.76. The experimental data [2,3] produced Markstein numbers of 3.75 for methane and 80:20 methane:hydrogen mixtures, and a value of 1.6 for 50:50 mixtures. Except at low turbulence levels, SCOPE assumes that the turbulent burning velocity is inversely proportional to the cube root of Ma. This results in a turbulent burning velocity for the 50:50 mixture approximately $(1.6 / 3.75)^{-1 / 3}=1.33$ times greater than that for methane or an 80:20 mixture. Two correlations for turbulent burning velocity were also derived directly from the experimental data [3], one correlation for 50:50 mixtures and the other for methane or 80:20 mixtures. Comparing these correlations suggest an increase in turbulent burning velocity for the 50:50 mixture of about 1.46 , which is only slightly more than suggested by the existing approach taken within SCOPE. Hence the existing correlations used to calculate the turbulent burning velocity were retained, but the appropriate Markstein numbers used.

\subsection{Model Predictions}

To validate the model against the experimental data described in Section 3, the geometry of the test rig was formulated in the correct form for SCOPE as a series of grids. To obtain 
good predictions it was found that the obstacle supports at the walls of the test rig needed to be included in the description of the congestion in addition to the pipework obstacles themselves.

SCOPE was then used to simulate all the experiments ignited at the rear of the enclosure (Tests 6, 7, 8, 9 and 10). The predicted overpressure and flame speed were then compared with the experimental data as detailed in Table 1. Figure 8 shows the comparison of flame speed at the vent and Figure 9, the comparison of predicted and measured maximum overpressures.

When comparing predictions of explosion behaviour (especially maximum overpressure) with experimental data, two factors must be considered. Firstly, the variability of measured maximum overpressure from apparently identical explosions and secondly the degree of accuracy realistically expected from explosion models. In a study of the variability of explosion phenomena [8], the maximum overpressures measured was found to vary significantly within a series of nominally identical large scale experiments. A study of the capability of explosions models (both CFD and phenomenological) [9] showed that significant differences between predictions and data can also be expected. It is noteworthy that the criteria used to assess model performance in that study was the ability to predict within a factor of 2 (or 0.5 ) of the measured value [9]. Ledin [10] also applies the same criteria in his review of the predictive performance of explosion models. (Clearly, a model which provides conservative predictions is preferable).

As can be seen from Table 1, the predictions of maximum overpressure from the modified SCOPE model are all within a factor of 1.76 of the measured value and in 3 cases considerably better. The predicted flame speed at the vent showed even better agreement with the data and all the predictions were on the conservative side. 


\section{Conclusions}

Large scale experimental data on the severity of confined vented explosions have been obtained for methane:hydrogen mixtures containing up to $50 \%$ hydrogen by volume. Explosions severity (overpressure) increased with increasing hydrogen fraction, although the increase was modest for the addition of $20 \%$ of hydrogen. The addition of pipework congestion also increased overpressures significantly and the location of the ignition was an important factor. These results are encouraging for the Naturalhy project, suggesting that the level of hydrogen addition envisaged is likely to result in only a modest increase in the explosion severity.

The Shell model SCOPE was modified and then used to predict some of these natural gas/hydrogen explosions. Reasonable agreement was achieved and this suggests that SCOPE would provide a means of predicting confined vented explosions of this type involving natural gas/hydrogen mixtures in other geometries of enclosure and with differing levels of congestion.

\section{Acknowledgements}

The authors would like to thank the European Commission for providing the financial support for this study as part of the Naturalhy project.

\section{References}

1. Wu, Y., Lu, Y., Al-Rahbi, I.S., Kalghatgi, G.T., Prediction of the Liftoff, Blowout and Blowoff Stability Limits of Pure Hydrogen and Hydrogen/Hydrocarbon Mixture Jet Flames, International Journal of Hydrogen Energy, 2009 doi:10.1016/j.ijhydene.2009.01.084 
2. Burlaka, A.A., Fairweather, M., Ormsby, M.P., Sheppard, C.G.W., Woolley, R., The Laminar Burning Properties of Premixed Methane-Hydrogen Flames Determined Using a Novel Analysis Method, Third European Combustion Meeting, 2007.

3. Fairweather, M., Ormsby, M.P., Sheppard, C.G.W., Woolley, R., Turbulent Burning Rates of Methane and Methane-Hydrogen Mixtures, Combustion and Flame, 2009 doi:10.1016/j.combustflame.2009.02.001

4. Puttock, J.S., Yardley, M.R., Cresswell, T.M., Prediction of Vapour Cloud Explosions using the SCOPE Model, J. of Loss Prevention in the Process Industries 13:419-431, 2000. doi:10.1016/S0950-4230(99)00045-5

5. Metghalchi, Mohamad, Keck, James C., Burning velocities of mixtures of air with methanol, isooctane, and indolene at high pressure and temperature, Combustion and Flame V48, pp191-210, 1982. doi:10.1016/0010-2180(82)90127-4

6. Mumby, C., Large Scale Engineering Modelling of Vapour Cloud Explosions and Jet Fires of Natural Gas/Hydrogen Fuel Mixtures, PhD Thesis, Loughborough University U.K, 2010.

7. Puttock, J., Note on turbulent burning velocity, Shell Global Solutions, Private Communication, 2008.

8. Evans, J.A., Exon, R. and Johnson, D.M., The Repeatability of Large Scale Explosion Experiments, Offshore Technology Report OTO 1999 042, Health and Safety Executive, UK, 1999. 
9. Selby, C.A. and Burgan, B.A., Blast and Fire Engineering for Topside Structures Phase 2, Final Summary Report, SCI-P-253, The Steel Construction Institute, UK, 1998. ISBN 1859420788.

10. Ledin, H.S., A Review of State-of-the-Art in Gas Explosion Modelling, Health and Safety Laboratory Report, UK, HSL/2002/02, 2002.

Figure 1: Schematic of the experimental arrangement

Figure 2: Location of the pressure transducers

Figure 3: Overpressure within Enclosure during Test 2

Figure 4: Overpressure within Enclosure during Test 9

Figure 5: Flame development through the enclosure

Figure 6: Relationship between flame speed at the vent and maximum overpressure

Figure 7: Maximum Overpressure in Enclosure with Different Hydrogen Concentrations

Figure 8: Comparison of Predicted and Measured Flame Exit Speed

Figure 9: Comparison of Predicted and Measured Overpressure

Table 1: Summary of the test programme and results 


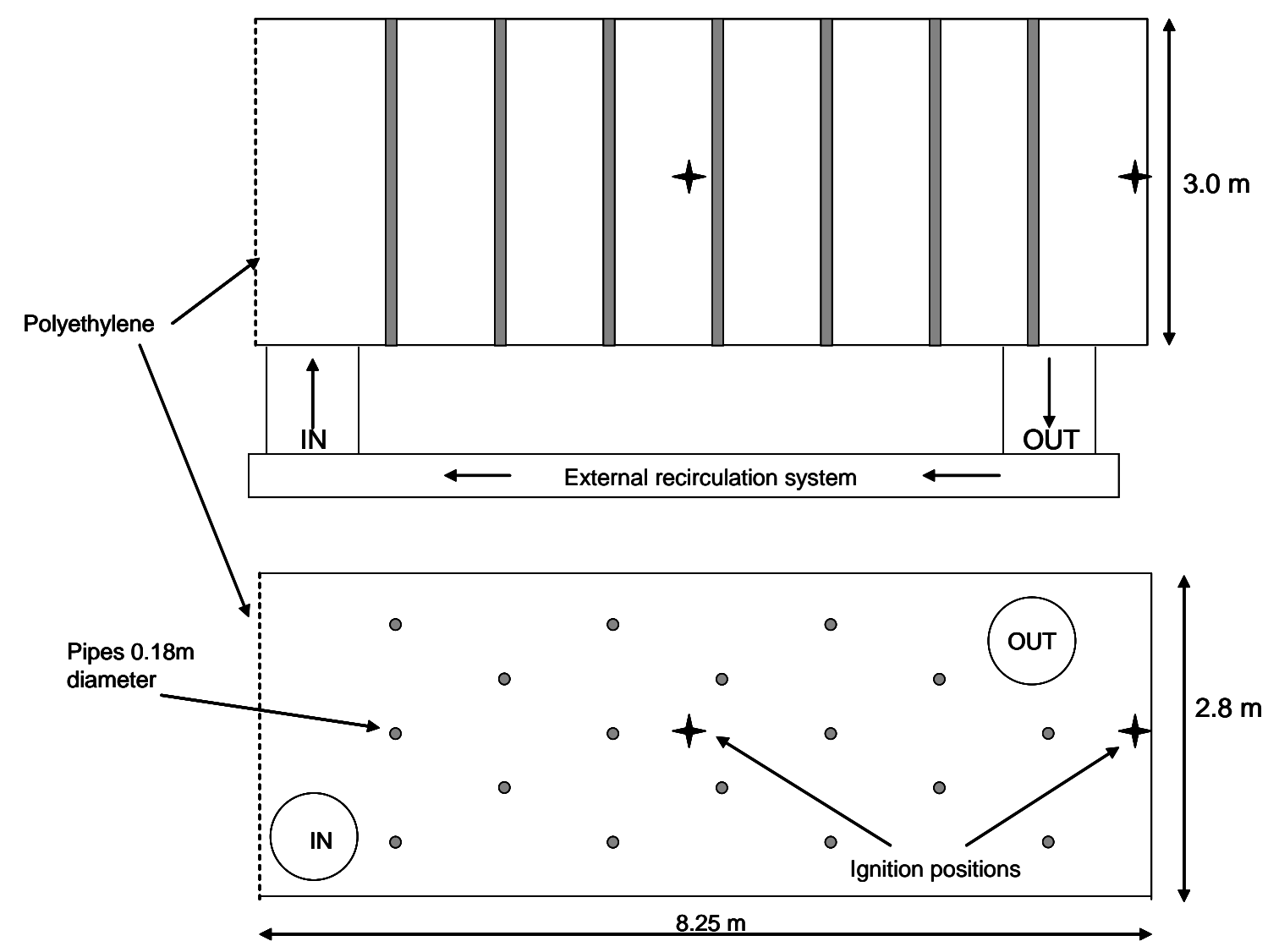

Figure 1: Schematic of the Experimental Arrangement 


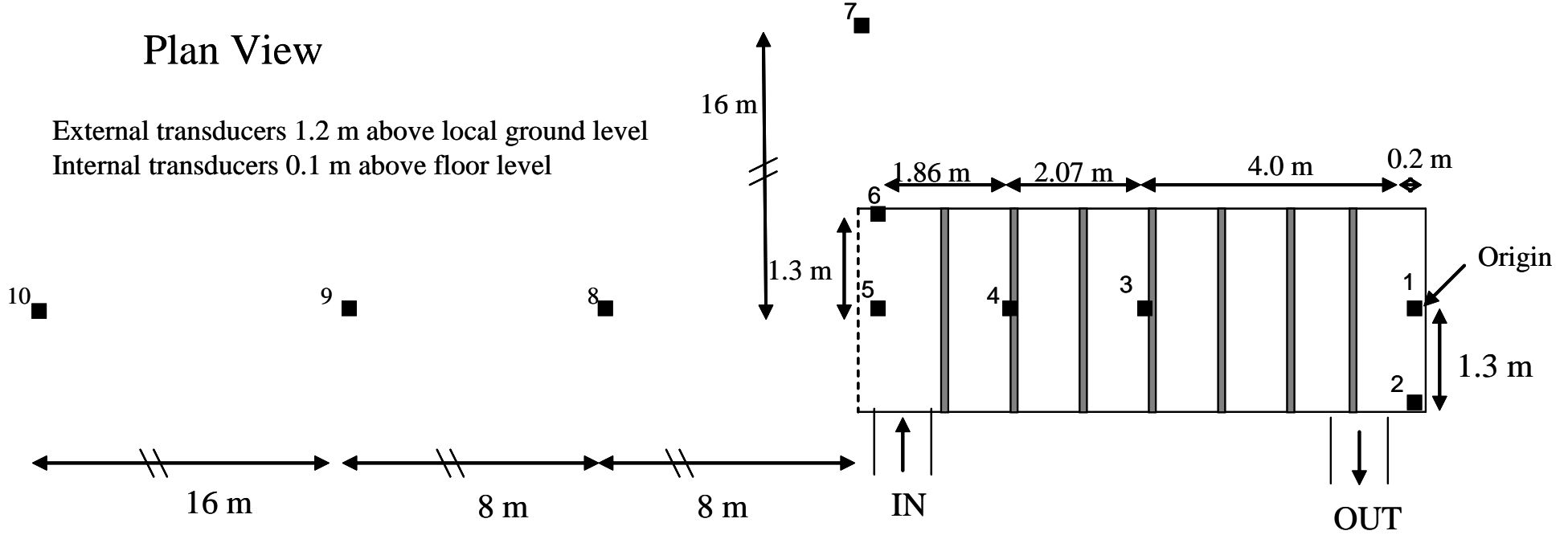

Figure 2: Location of the pressure transducers 


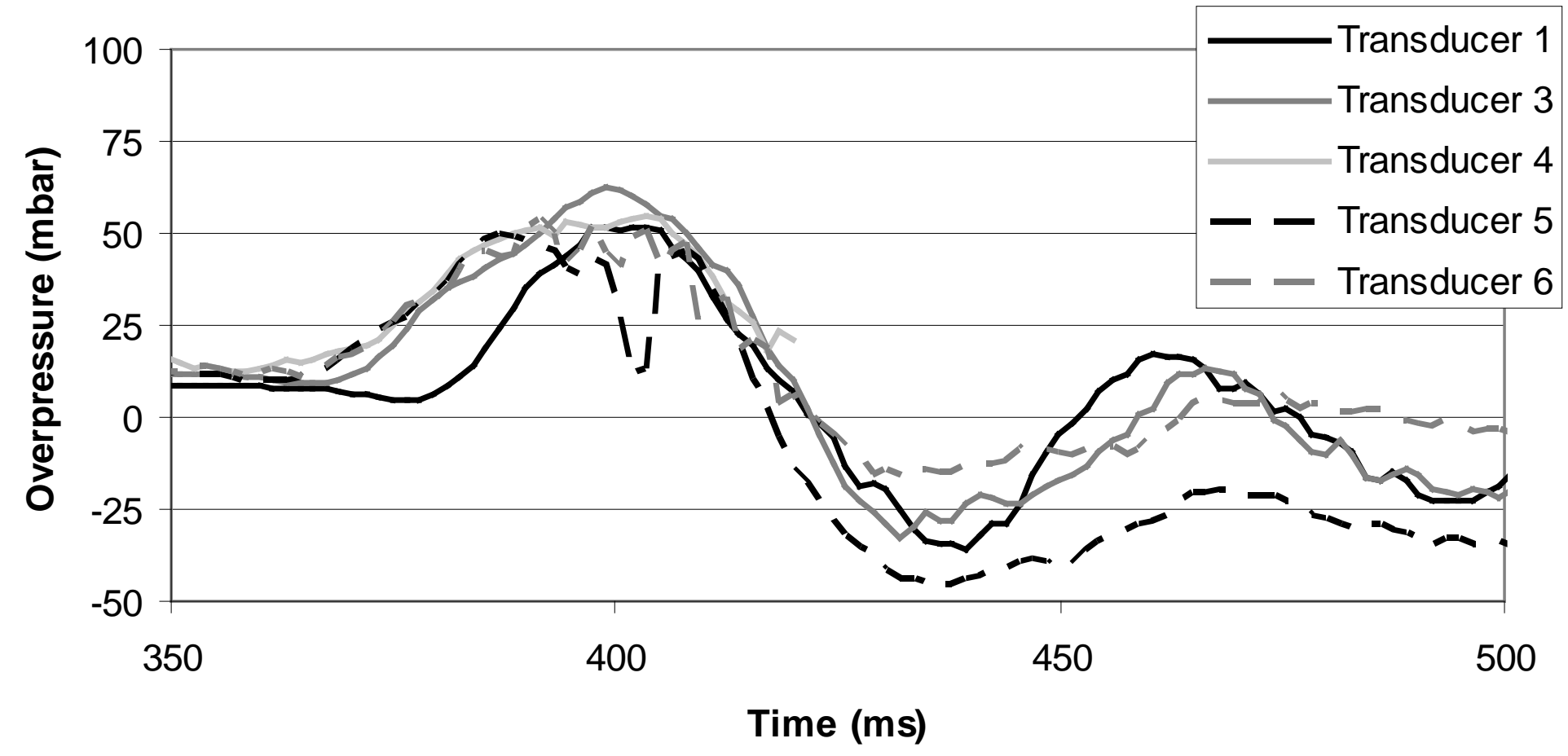

Figure 3: Overpressure within Enclosure during Test 2 


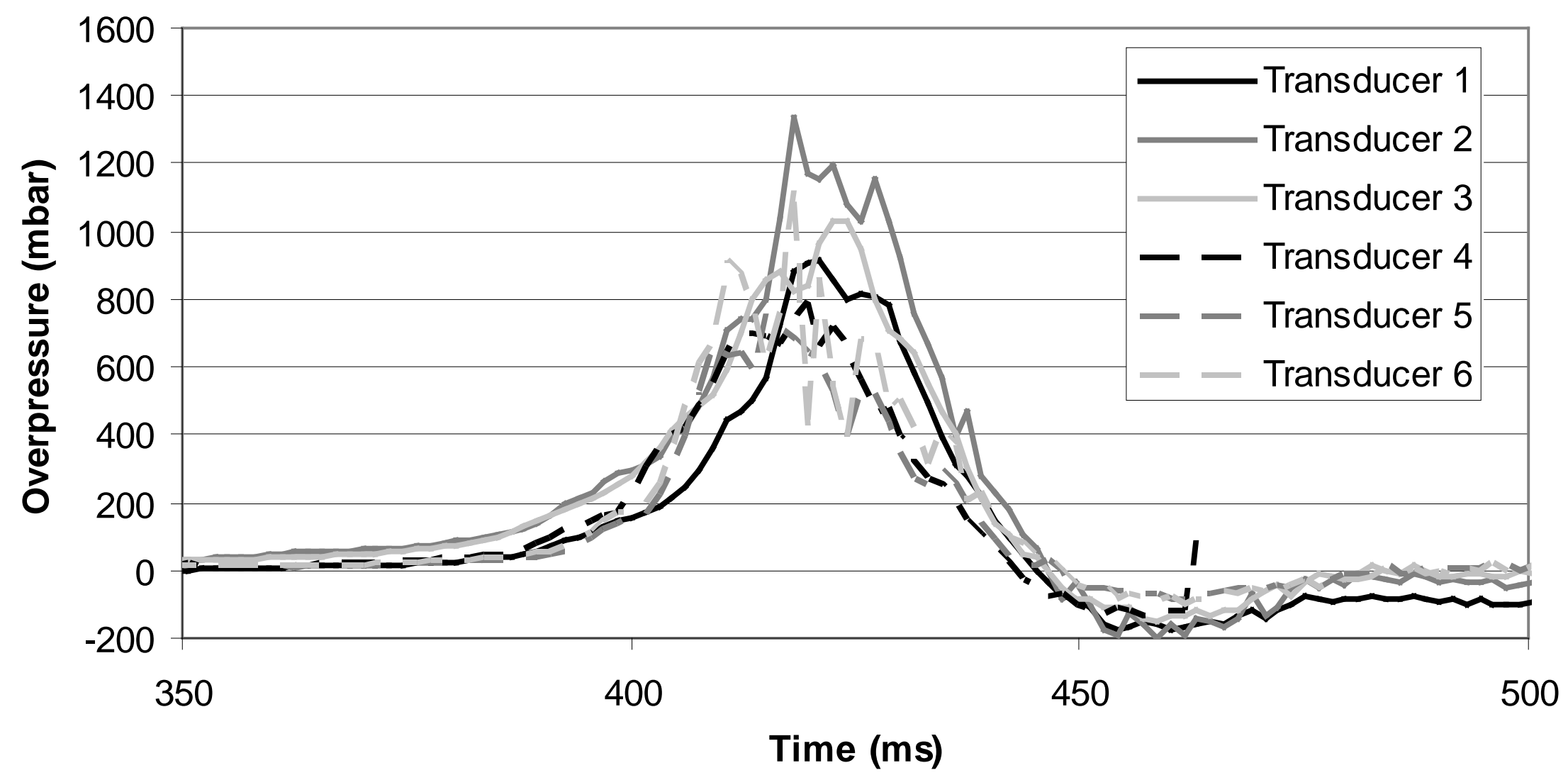

Figure 4: Overpressure within Enclosure during Test 9 


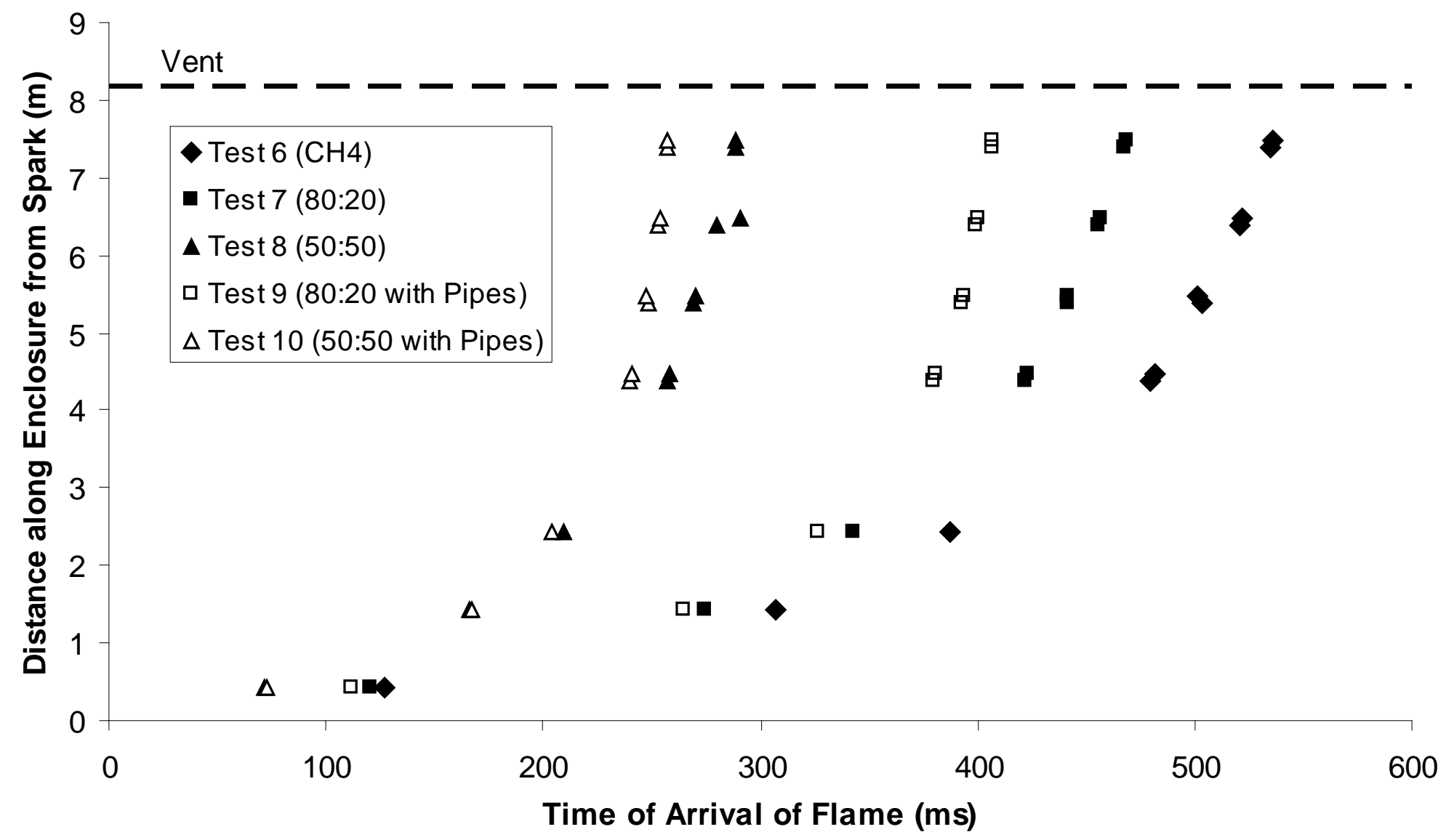

Figure 5: Flame development through the enclosure 


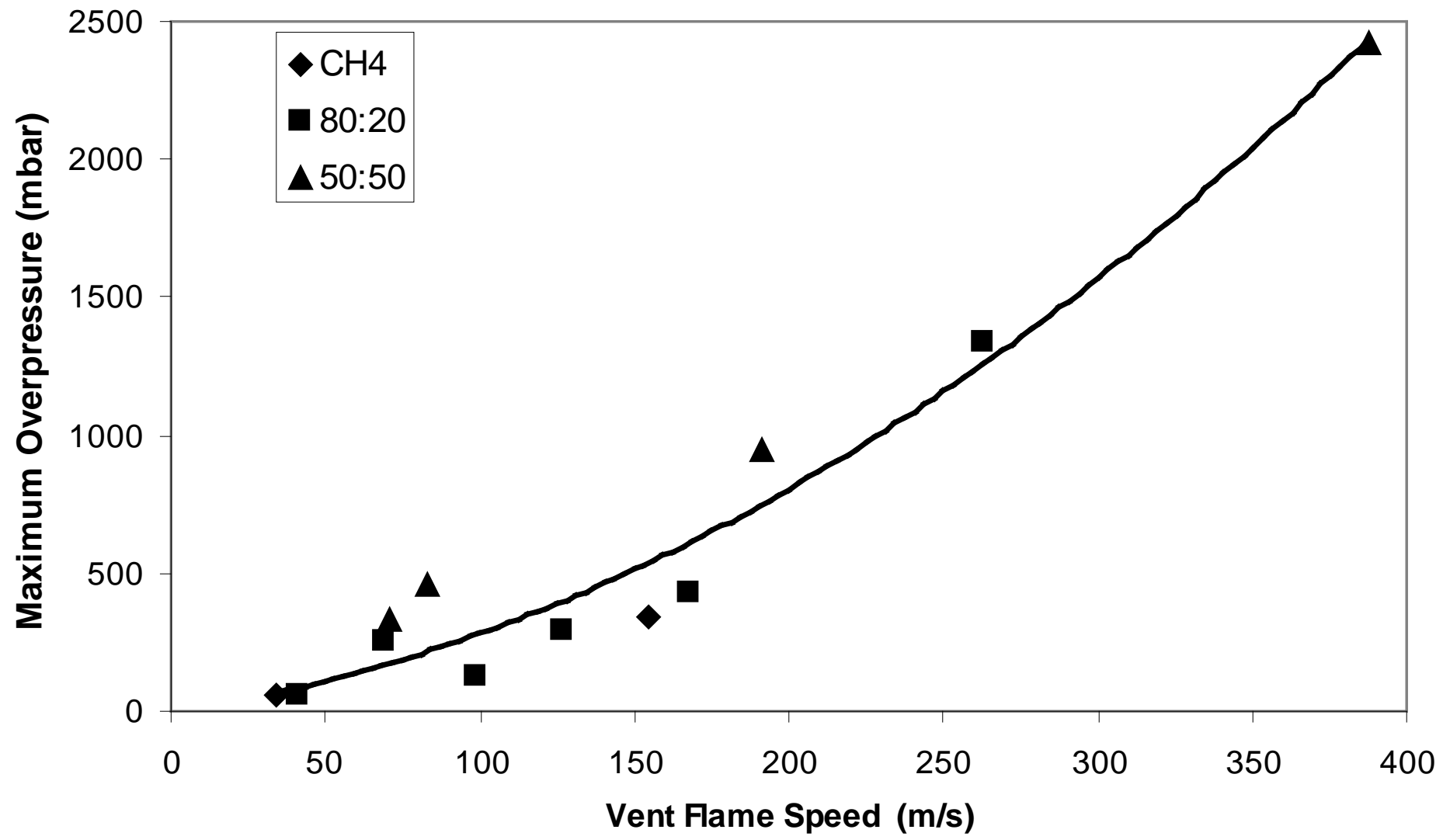

Figure 6: Relationship between flame speed at the vent and maximum overpressure 


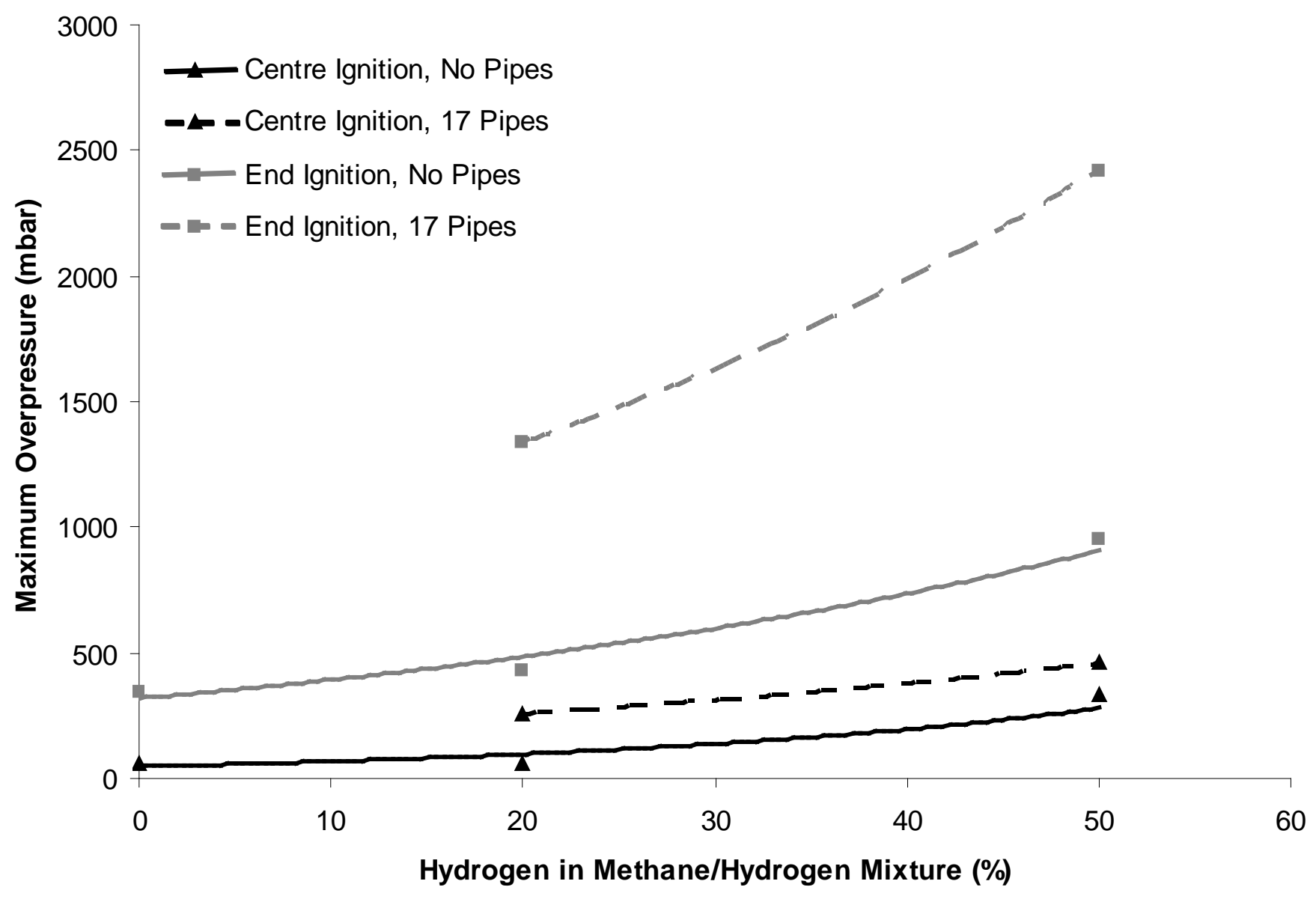

Figure 7: Maximum Overpressure in Enclosure with Different Hydrogen Concentrations 


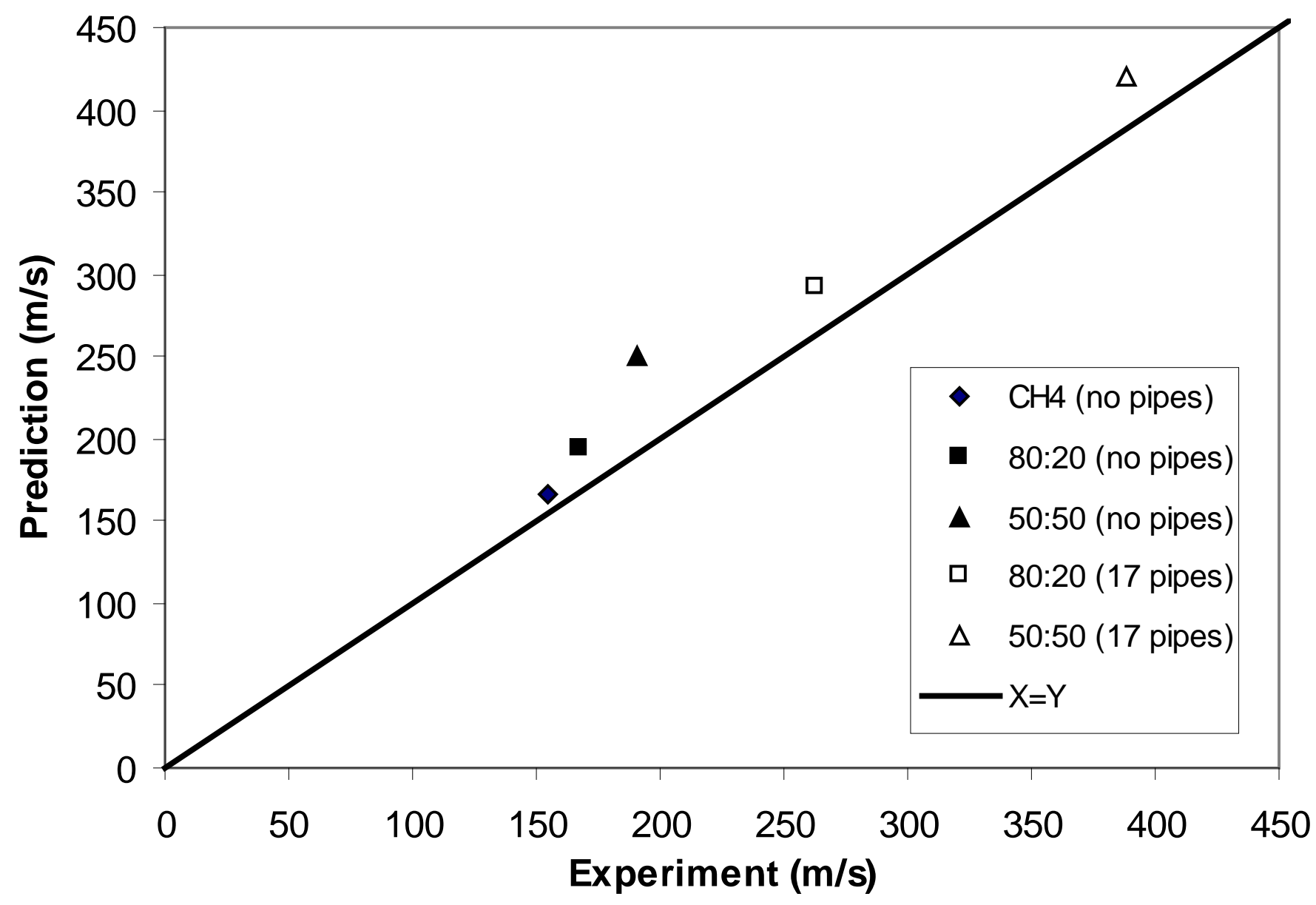

Figure 8: Comparison of Predicted and Measured Flame Exit Speed 


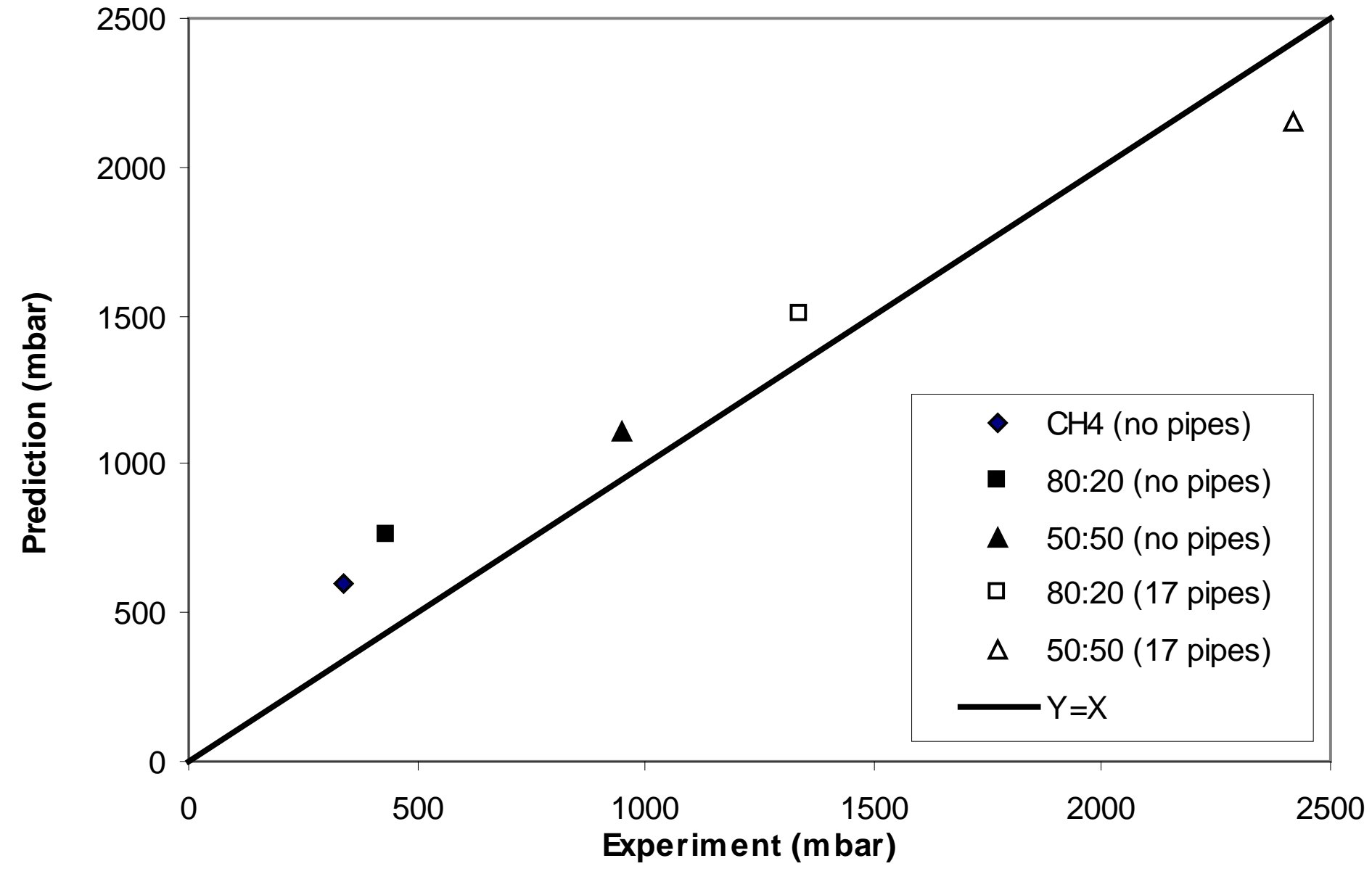

Figure 9: Comparison of Predicted and Measured Overpressure 


\begin{tabular}{|c|c|c|c|c|c|c|c|c|c|c|}
\hline \multirow[b]{2}{*}{ Test } & \multirow[b]{2}{*}{ Fuel } & \multirow[b]{2}{*}{$\begin{array}{l}\text { Pipework } \\
\text { Congestion }\end{array}$} & \multirow[b]{2}{*}{$\begin{array}{l}\text { Ignition } \\
\text { Location }\end{array}$} & \multicolumn{3}{|c|}{ EXPERIMENTAL MEASUREMENTS } & \multicolumn{4}{|c|}{ SCOPE MODEL PREDICTIONS } \\
\hline & & & & $\begin{array}{c}\text { Average } \\
\text { Peak } \\
\text { Overpressure } \\
\text { (mbar) }\end{array}$ & $\begin{array}{l}\text { Maximum } \\
\text { Overpressure } \\
\text { (mbar) }\end{array}$ & $\begin{array}{l}\text { Flame } \\
\text { Speed } \\
\text { from } \\
\text { Vent } \\
\left(\mathrm{m} \mathrm{s}^{-1}\right)\end{array}$ & $\begin{array}{l}\text { Maximum } \\
\text { Overpressure } \\
\text { (mbar) }\end{array}$ & $\begin{array}{c}\% \\
\text { difference }\end{array}$ & $\begin{array}{c}\text { Flame } \\
\text { Speed } \\
\text { from } \\
\text { Vent } \\
\left(\mathrm{m} \mathrm{s}^{-1}\right)\end{array}$ & $\begin{array}{c}\% \\
\text { difference }\end{array}$ \\
\hline 1 & Methane & No & Centre & 44 & 62 & 34 & & & & \\
\hline 2 & $80: 20$ mix & No & Centre & 55 & 63 & 41 & & & & \\
\hline 3 & $50: 50 \mathrm{mix}$ & No & Centre & 196 & 331 & 71 & & & & \\
\hline 4 & $80: 20$ mix & Yes & Centre & 153 & 258 & 69 & & & & \\
\hline 5 & 50:50 mix & Yes & Centre & 276 & 459 & 83 & & & & \\
\hline 6 & Methane & No & Rear & 237 & 342 & 155 & 597 & $+75 \%$ & 167 & $+8 \%$ \\
\hline 7 & $80: 20$ mix & No & Rear & 287 & 432 & 168 & 760 & $+76 \%$ & 195 & $+16 \%$ \\
\hline 8 & 50:50 mix & No & Rear & 668 & 950 & 191 & 1112 & $+17 \%$ & 251 & $+31 \%$ \\
\hline 9 & $80: 20$ mix & Yes & Rear & 1033 & 1338 & 263 & 1501 & $+12 \%$ & 293 & $+11 \%$ \\
\hline 10 & $50: 50$ mix & Yes & Rear & 1816 & 2421 & 388 & 2153 & $-11 \%$ & 421 & $+9 \%$ \\
\hline
\end{tabular}

Table 1: Summary of the test programme and results 